Байкальский государственный университет эконолики и права, г. Иркутск, Российская Федерация

А. А. Балдина

Байкальский государственный университет эконолики и права, г. Иркутск, Российкая Федерация

\author{
РОЛЬ МАЛОГО ПРЕДПРИНИМАТЕЛЬСТВА \\ В СОЦИАЛЬНО-ЭКОНОМИЧЕСКОМ РАЗВИТИИ \\ МОНОГОРОДОВ ИРКУТСКОЙ ОБЛАСТИ
}

\begin{abstract}
АНнотАЦия. В настоящее время вопрос о развитии моногородов с тяжелым социально-экономическим положением стоит особенно остро. Одним из действительно эффективных способов выведения этих монопрофильных городов из кризиса является диверсификация их экономики, а именно развитие малого предпринимательства. В статье рассматривается понятие монопрофильного муниципалитета, изучается социально-экономическая ситуация, анализируется статистика количества моногородов в России и Иркутской области в 2014 г., обосновывается роль деятельности субъектов малого предпринимательства. В связи с этим анализируется состояние малого предпринимательства в моногородах Иркутской области, в том числе в г. Байкальске, как в наиболее кризисном монопрофильном муниципалитете данного региона. Делается вывод о необходимости развития малого предпринимательства в моногородах Иркутской области при помощи государственной поддержки для улучшения их социально-экономического положения.

кЛЮчЕВЫЕ СЛОВА. Моногород; развитие малого предпринимательства; статистика моногородов Иркутской области; малое предпринимательство в городе Байкальск; корреляционный анализ; зависимость развития малого предпринимательства от государственной поддержки.
\end{abstract}

ИНФОРМАЦИЯ О СТАТЬЕ. Дата поступления 25 мая 2015 г.; дата принятия к печати 19 ноября 2015 г.; дата онлайн-размещения 30 ноября 2015 г.

Yu. A. Skorobogatova Baikal State University of Economics and Law, Irkutsk, Russian Federation

A. A. Baldina

Baikal State University of Economics and Law, Irkutsk, Russian Federation

\title{
ROLE OF SMALL BUSINESS IN SOCIO-ECONOMIC DEVELOPMENT OF SINGLE-INDUSTRY TOWNS IN IRKUTSK OBLAST
}

\begin{abstract}
Currently, the issue of developing single-industry towns with a heavy social and economic situation is particularly acute. One of the really effective ways of removing these single-industry towns from the crisis is to diversify their economies, namely, development of small business. The article considers the concept of single-industry municipality, investigates the socio-economic situation, analyses statistics of the number of single-industry towns in Russia and Irkutsk Oblast in 2014, substantiates the role of small business entities. In this regard, it analyses the state of small business in single-industry towns in Irkutsk Oblast, including the town of Baikalsk as the most distressed single-industry municipality in this region. A conclusion is drawn about the necessity of developing small businesses in single-industry towns of Irkutsk Oblast with the help of governmental support to improve their socio-economic situation.
\end{abstract}

(C) Ю.А.Скоробогатова, А.А. Балдина

\section{Baikal Research Journal}


KEYWORDS. Single-industry town; small business development; statistics of single-industry towns of Irkutsk Oblast; small businesses in the town of Baikalsk; correlation analysis; dependence of small business development on governmental support.

ARTICLE INFO. Received May 25, 2015; accepted November 19, 2015; available online November 30, 2015.

Развитие малого предпринимательства является обязательным требованием успешного функционирования современной рыночной экономики. Мировой опыт доказывает, что отсутствие этого экономического сектора может негативно отразиться в целом на всей экономической системе страны и препятствовать ее гармоничному развитию, ведь, прежде всего этот сектор оказывает влияние на темп экономического роста в стране и на качество ее валового национального продукта (ВНП).

Малое предпринимательство в силу своих особенностей имеет ярко выраженную муниципальную и региональную направленность. Малые предприятия обычно ведут свою деятельность, исходя из потребностей местного рынка и возможностей его насыщения, а также из структуры и объема локального спроса. В условиях экономической самостоятельности муниципалитетов и регионов малое предпринимательство должно рассматриваться как необходимое средство улучшения структуры и в целом состояния муниципальной и региональной экономики, в том числе это касается экономики моногородов [3].

Для лучшего понимания современного состояния экономики моногородов рассмотрим сущность понятия «моногород». В настоящее время четкого и установленного законом определения «моногород» не существует, это говорит о недостаточном регулировании экономики монопрофильных муниципалитетов и слабости их институционального статуса. Сущность такого феномена, как «монопрофильность», состоит в жесткой зависимости между финансово-экономическим положением градообразующего предприятия и состоянием всех сфер жизнедеятельности города.

Проанализировав научную литературу, можно дать следующее определение понятию «моногород»: под монопрофильным муниципалитетом или моногородом понимается муниципальное образование, где находится крупное предприятие или группа предприятий, объединенных одним технологическим циклом, где занято более 20 \% экономически активного населения города, а доля выпускаемой продукции составляет более 50 \% от общего объема отгруженной продукции [8].

На данный момент в России, по подсчетам Министерства экономического развития РФ, существует 313 моногородов в 61 субъекте РФ, которые охватывают около 15,5 млн чел. В Иркутской области находится 8 монопрофильных муниципалитетов с населением более 380 тыс. чел. (рис. 1).

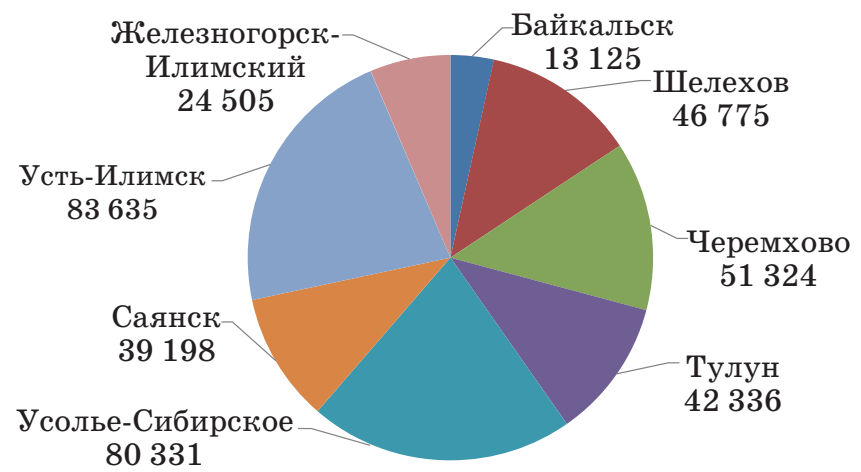

Рис. 1. Численность населения лоногородов Иркутской области в 2014 г., чел. (Составлено по данныл: URL : http://irkutskstat.gks.ru/wps/wcm/connect/rosstat_ts/ irkutskstat/ru/municipal_statistics/main_indicators/).

\section{Baikal Research Journal}


В зависимости от рисков ухудшения социально-экономической ситуации все эти моногорода в Иркутской области делятся на 3 категории: со сложной социально-экономической ситуацией (Байкальск и Шелехов); с имеющимися рисками ухудшения социально-экономического положения (Черемхово, Тулун, Усолье-Сибирское, Саянск); со стабильной ситуацией (Усть-Илимск и Железногорск-Илимский $)^{1}$. Таким образом, самым многочисленным моногородом в Иркутской области является Усть-Илимск, который относится к моногородам со стабильной ситуацией, а самым малочисленным - Байкальск, который находится в сложной социально-экономической ситуации (см. рис. 1).

Большая часть моногородов России образована при предприятиях деревообрабатывающей и лесной промышленности (20\% от их общего числа), на машиностроение приходится $17 \%$ моногородов, на пищевую промышленность - 14 \% моногородов, на топливную промышленность - $11 \%$ моногородов, оставшаяся часть (38 \% ) распределена по другим отраслям (рис. 2).

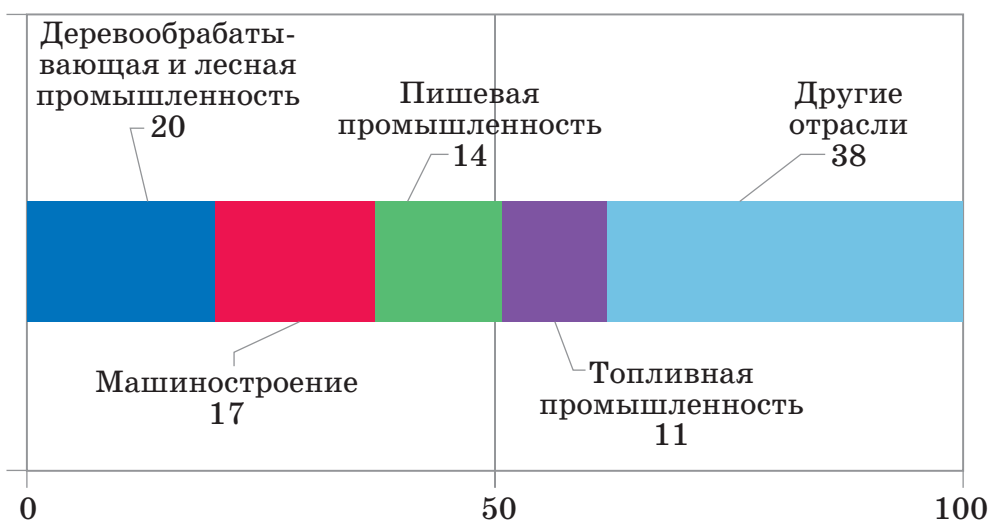

Рис. 2. Структура распределения моногородов по отраслям экономики в 2014 г., \%

Мировой финансово-экономический кризис 2008-2009 гг. ввел многие градообразующие предприятия в очень тяжелое положение. В связи с этим моногорода сейчас находятся в условиях постоянно растущей безработицы, снижения доходов населения, миграции трудоспособного молодого населения, сильной зависимости городского бюджета от налогов, которые платит градообразующее предприятие, недостаточности создающихся рабочих мест, низких показателей рождаемости. Все этого говорит о том, что моногорода сейчас находятся в зоне риска перехода в группу депрессивных городов [1].

В 89 монопрофильных муниципалитетах России, по данным Министерства экономического развития РФ за 2014 г., ситуация является относительно благополучной: в этих городах уровень безработицы не превышает среднего по стране $(5,2 \%)$. На данный момент безработных больше, чем в среднем по стране, зафиксировано в 149 моногородах, а безработица в 2-3 раза выше среднего значения - в 75 (рис. 3 ). Перечисленные факторы становятся причиной массового миграционного оттока жителей из монопрофильных городов.

Таким образом, проблема функционирования и развития моногородов встала очень остро и приобрела стратегическое значение не только для отдельных регионов и муниципалитетов, но и для экономики России в целом. Одним из самых эффективных способов развития моногородов, находящихся в тяжелом социально-эконо-

${ }^{1}$ Об утверждении перечня монопрофильных муниципальных образований Российской Федерации (моногородов) : распоряжение Правительства РФ от 29 июля 2014 г. № 1398-р.

\section{Baikal Research Journal}

электронный научный журнал Байкальского государственного университета экономики и права 
мическом состоянии, является дифференциация экономики путем развития малого предпринимательства, так как оно способно снизить зависимость развития города от деятельности градообразующего предприятия, социальную напряженность и уровень безработицы, увеличить обеспеченность населения города товарами и услугами и др. [5].

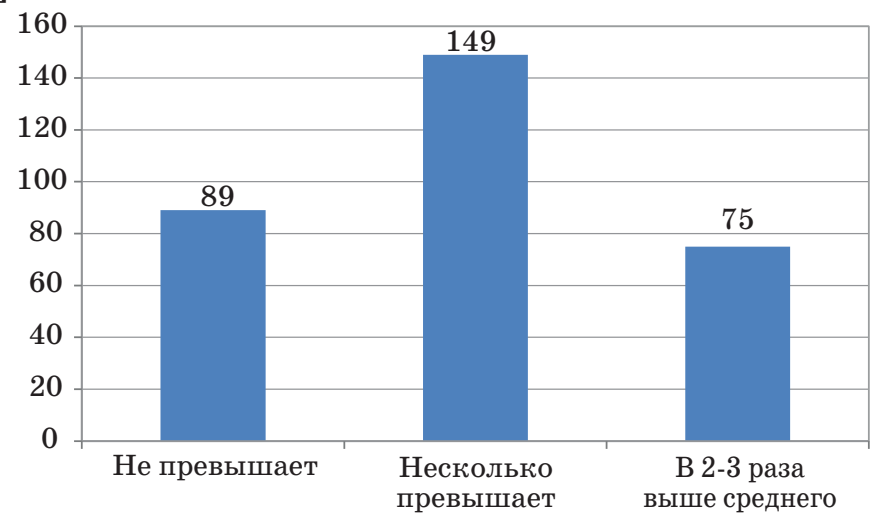

Рис. 3. Уровень безработицы в моногородах России в 2014 г. (Составлено по: [4])

На данный момент в моногородах Иркутской области малое предпринимательство развито очень слабо: их доля малых в большинстве монопрофильных муниципальных образований составляет от 1 до $13 \%$, что гораздо ниже среднего уровня по России [6]. Современное состояния малого предпринимательства в моногородах Иркутской области проанализируем на примере таких городов, как Байкальск, Шелехов, Черемхово, Тулун, Усолье-Сибирское, Саянск, Усть-Илимск и Железногорск-Илимский.

По данным Иркутскстата за 2013 г., самая большая численность малых предприятий наблюдается в г. Шелехове (809 единиц) и Усолье-Сибирское (647 единиц), при чем количество малых предприятий в г. Шелехов на 25 \% больше этого же показателя в г. Усолье-Сибирское, в 2,7 раза больше чем в Тулуне и в 13 раз больше чем в Байкальске (рис. 4). Такое большое число субъектов малого предпринимательства в этих городах вызвано их близостью к областному центру - г. Иркутску. В таких городах, как Тулун, Черемхово, Саянск, Усть-Илимск и З゚елезногорск-Илимский, видна не сильно большая разница в количестве малых предприятий. Самое меньшее число малых предприятий наблюдается в г. Байкальске и составляет всего 62 единицы, не смотря на достаточную близость этого моногорода к Иркутску. Так, например, в г. Братске, не являющемся моногородом, в 2013 г. насчитывалось 1554 малых предприятий, это почти в 2 раза больше, чем в г. Шелехове, в 6,6 раза больше, чем в г. Черемхово, в 25 раз больше, чем в г. Байкальск. Из этого можно сделать вывод, что г. Байкальск на данный момент является самым кризисным из всех монопрофильных муниципалитетов Иркутской области.

Для лучшего понимания степени тяжести социально-экономического положения в г. Байкальске проведем более полный анализ состояния малого предпринимательства. Отметим, что в последние годы здесь возрастает роль деятельности субъектов малого предпринимательства:

- удельный вес объема отгруженной продукции собственного производства малых предприятий в общегородском объеме вырос в полтора раза - с 27,8 \% в 2011 г. до 41,5 \% в 2013 г., что положительно характеризует деятельность малого предпринимательства в Байкальске;

\section{Baikal Research Journal}


- доля экономически активного населения, занятого на малых предприятиях, постепенно увеличивается — с 9,6 \% в 2009 г. до 10,5 \% в 2013 г., однако рост этого показателя происходит слишком низкими темпами (темп прироста 9,3 \% за 5 лет);

- удельный вес доходов от малых предприятий в бюджете Байкальского городского поселения поднялся с 17,3 \% в 2011 г. до 19,8 \% в 2013 г. (табл. 1).

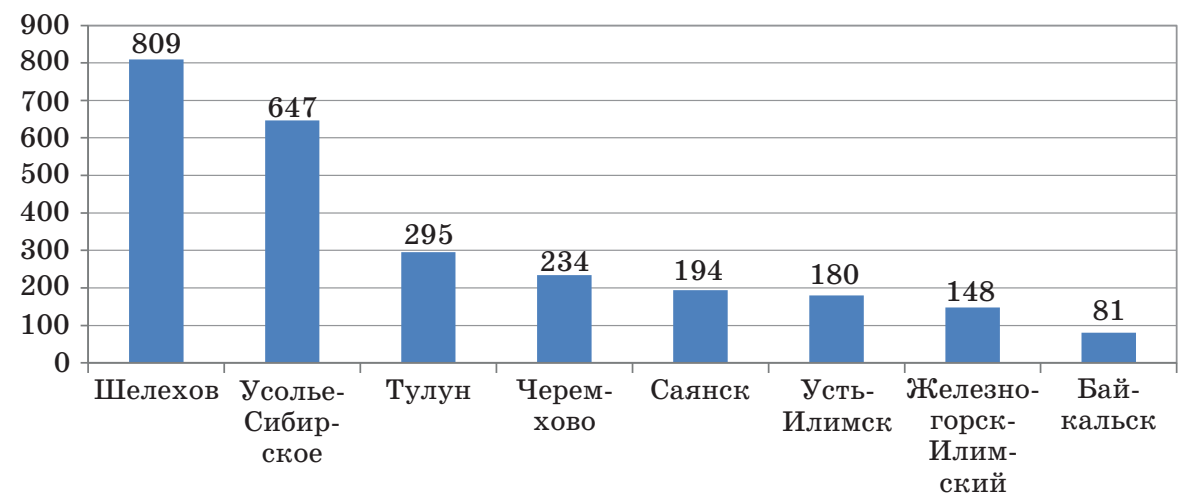

Рис. 4. Распределение лоногородов Иркутской области по количеству находящихся в них субъектов малого предпринилательства в 2013 г.

(Составлено по: URL : http://irkutskstat.gks.ru/)

Доходы бюджета г. Байкальск в 2011-2013 г2., млн р.

Таблица 1

\begin{tabular}{|l|r|r|r|r|r|}
\hline \multicolumn{1}{|c|}{ Доходы } & 2011 & 2012 & 2013 & $\begin{array}{c}\text { Динамика } \\
(2011 / 2012), \\
\%\end{array}$ & $\begin{array}{c}\text { Динамика } \\
(2013 / 2012), \\
\%\end{array}$ \\
\hline $\begin{array}{l}\text { Поступления от субъектов малого и среднего } \\
\text { предпринимательства, из них: }\end{array}$ & 17,3 & 18,4 & 19,8 & 106,3 & 107,6 \\
\hline Налог на доходы физических лиц & 9,2 & 9,7 & 9,8 & 105,4 & 101,0 \\
\hline Земельный налог & 3,7 & 4,8 & 5,5 & 129,7 & 114,6 \\
\hline Аренда земельных участков & 5,72 & 6,3 & 6,9 & 110,1 & 109,5 \\
\hline Всего доходов & 143,9 & 151,9 & 132,5 & 105,5 & 87,2 \\
\hline
\end{tabular}

Составлено по: Об утверждении муниципальной программы «Развитие малого и среднего предпринимательства в Байкальском муниципальном образовании на период 2014-2018 годы» : постановление адм. Байкал. гор. поселения от 18 марта 2014 г. № 143-п.

Таким образом, можно сделать вывод, что изменение поступлений от малых предприятий имеет положительные тенденции. Так, например, с 2011 по 2013 г. этот показатель увеличился на 2,5 млн р. в абсолютном выражении, или на 14,5 \% в относительном выражении.

Субъекты малого предпринимательства в г. Байкальске решают такие важные задачи, как поступление доходов в местный бюджет, насыщение потребительского рынка товарами и услугами, сокращение уровня безработицы. Однако в г. Байкальске находится очень мало субъектов малого предпринимательства: на 2012 г. зарегистрировано 62 единицы (в расчете на 1000 чел. это число составляет 4 единицы). В период с 2010 по 2012 г. наблюдается положительная динамика изменения количества малых предприятий (табл. 2): абсолютный прирост их числа за анализируемый период составил 33 единицы, т. е. произошло увеличение в 2,1 раза.

Численность занятых в малом предпринимательстве также имеет тенденцию на увеличение. С 2010 по 2012 г. происходит рост этого показателя на 593 чел. в абсолютном выражении, или на $47,1 \%$ в относительном выражении. Если рассматри-

\section{Baikal Research Journal}

электронный научный журнал Байкальского государственного университета экономики и права 
вать изменение оборота малых предприятий, то можно сказать, что за три анализируемых года оборот вырос на 128,1 млн р., или на $21 \%$.

Таблица 2

Основные показатели развития малого предпринилательства в городе Байкальск за 2010-2012 г2.

\begin{tabular}{|c|c|c|c|}
\hline Показатель & 2010 & 2011 & 2012 \\
\hline Число малых предприятий & 29 & 33 & 62 \\
\hline В расчете на 1 тыс. чел. населения города & 1 & 2 & 4 \\
\hline Темп роста, \% & 12,7 & 13,8 & 87,9 \\
\hline $\begin{array}{l}\text { Среднесписочная численность работников, занятых на малых } \\
\text { предприятиях }\end{array}$ & 1257 & 1619 & 1850 \\
\hline Темп роста, \% & 10,4 & 28,8 & 14,3 \\
\hline $\begin{array}{l}\text { Доля среднесписочной численности работников малых пред- } \\
\text { приятий от совокупного количества экономически активного } \\
\text { населения (без внешних совместителей }\end{array}$ & 9,6 & 10,5 & 11,6 \\
\hline Оборот субъектов малого предпринимательства & 609,8 & 670,8 & 737,9 \\
\hline Темп роста, \% & 6 & 10 & 10 \\
\hline
\end{tabular}

Составлено по: Об утверждении муниципальной программы «Развитие малого и среднего предпринимательства в Байкальском муниципальном образовании на период 2014-2018 годы» : постановление адм. Байкал. гор. поселения от 18 марта 2014 г. № 143-п.

Сложившаяся отраслевая структура малого предпринимательства в г. Байкальске $^{2}$ (рис. 5) свидетельствует о преимущественном развитии субъектов малого предпринимательства в сфере торговли (55\%) и оказания услуг $(19 \%)$, что соответствует отраслевой структуре малого предпринимательства на уровне страны и области.

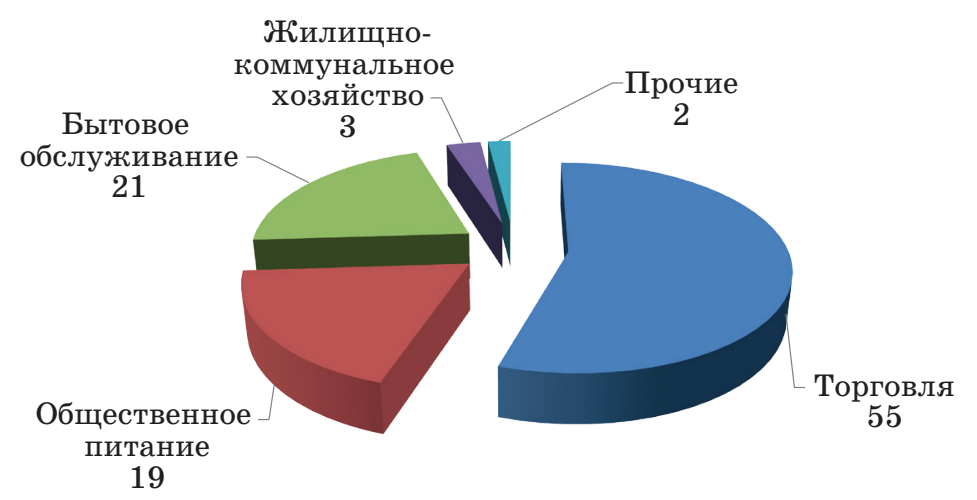

Рис. 5. Отраслевая структура малого предпринимательства в г. Байкальске в 2012 г., \%

Таким образом, малое предпринимательство в моногородах Иркутской области характеризуется очень низкими значениями количества малых предприятий, особенно это видно в г. ЗЖелезногорск-Илимский и Байкальске. В целом малое предпринимательство в г. Байкальске имеет тенденцию на увеличение эффективности своей работы. Однако его деятельность по-прежнему вносит слишком малый вклад в развитие этого моногорода в связи с его малой численностью.

Следовательно, малое предпринимательство в моногородах Иркутской области необходимо развивать и увеличивать эффективность деятельности субъектов мало-

${ }^{2}$ Об утверждении муниципальной программы «Развитие малого и среднего предпринимательства в Байкальском муниципальном образовании на период 2014-2018 годы» : постановление адм. Байкал. гор. поселения от 18 марта 2014 г. № 143-п.

\section{Baikal Research Journal}

электронный научный журнал Байкальского государственного университета экономики и права 
го предпринимательства с целью улучшения социально-экономического положения этих моногородов. Развитие малого предпринимательства в моногородах Иркутской области возможно только с помощью применения мер государственной поддержки и увеличения предпринимательской активности населения. Это подтверждается выводами корреляционного анализа, проведенного для выявления зависимости изменения количества субъектов малого предпринимательства (фактор $Y)^{3}$ от динамики размеров государственной финансовой поддержки малому предпринимательству $(\text { фактор } X)^{4}$ и от изменения предпринимательской активности (индекс предпринимательской активности - фактор $Z)^{5}$ в России за 2008-2013 гг. (рис. 6).

\begin{tabular}{|c|c|c|c|c|c|c|c|c|}
\hline $\mathrm{Y}$ & 1334,9 & 1602,5 & 1644,3 & 1836,4 & 2003 & 2063,1 & & \\
\hline $\mathrm{X}$ & 3613 & 18634 & 17820 & 17824 & 20800 & 19787 & & \\
\hline $\mathrm{Z}$ & 4,4 & 6 & 6,6 & 7,4 & 6,3 & 9,1 & & \\
\hline & & & & & & & & \\
\hline \multicolumn{9}{|c|}{ матрица выборочных коэффициентов корреляции } \\
\hline & & $Y$ & $x$ & $z$ & & & & t-статистин \\
\hline & $\mathrm{Y}$ & 1 & 0,81622 & 0,832602 & & & $\operatorname{tyx}=$ & 3,995935 \\
\hline & $\mathrm{x}$ & 0,81622 & 1 & 0,704932 & & & $\operatorname{tyz}=$ & 4,251811 \\
\hline & $\underline{z}$ & 0,832602 & 0,704932 & 1 & & & $\mathrm{t} \times \mathrm{z}=$ & 2,811112 \\
\hline & & & & & & & & \\
\hline & & & & & \multicolumn{3}{|c|}{$t(1-\alpha, n-2)$} & 2,776445 \\
\hline & \multicolumn{4}{|c|}{ доверительный интервал для p(y,x) } & & & $z(y, x)=$ & 1,145386 \\
\hline & 0,013799 & & 0,979168 & & & & $t_{1-\alpha}$ & 1,959964 \\
\hline & & & & & & & & \\
\hline & \multicolumn{5}{|c|}{ коэффициент множественной корреляции } & & & \\
\hline & 0,89316 & & & & & & & \\
\hline & & & & & & & & \\
\hline & \multicolumn{5}{|c|}{ множественный коэффициент детерминации } & & & \\
\hline & 0,797734 & & & & & & & \\
\hline & & & & & & & & \\
\hline & \multicolumn{5}{|c|}{ матрица частных коэффициентов корреляции } & & & \\
\hline & & Y & $\mathrm{x}$ & z & & & & \\
\hline & $\mathrm{Y}$ & 1 & 0,583668 & 0,627713 & & & & \\
\hline & $\mathrm{x}$ & 0,583668 & 1 & 0,079206 & & & & \\
\hline & Z & 0,627713 & 0,079206 & 1 & & & & \\
\hline & & & & & & & & \\
\hline & \multicolumn{3}{|c|}{ алгебраические дополнения } & & & & & \\
\hline & qyy $=$ & 0,50307 & & & & & & \\
\hline & $q x x=$ & 0,306773 & & & & & & \\
\hline & $q z z=$ & 0,333785 & & & & & & \\
\hline & qyx $=$ & $-0,22929$ & & & & & & \\
\hline & $q y z=$ & $-0,25722$ & & & & & & \\
\hline & $q x z=$ & $-0,02535$ & & & & & & \\
\hline & 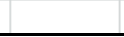 & & & & & & & \\
\hline
\end{tabular}

Рис.6. Корреляционный анализ

Проведя корреляционный анализ, можно сделать следующий вывод: выборочные частные коэффициенты корреляции показывают зависимость количества малых предприятий $Y$ от размеров субсидий малому предпринимательству $X$ и от

${ }^{3}$ Росстат. URL : http://www.gks.ru/wps/wcm/connect/rosstat_main/rosstat/ru/statistics/enterprise/reform/.

${ }^{4}$ Доклад о ходе реализации мер поддержки малого и среднего предпринимательства в 2010-2013 годах и основных направлениях развития малого и среднего предпринимательства на ближайшую и среднесрочную перспективу. URL : http://smb.gov.ru/statistics/navy/analitic/14952.html.

${ }^{5}$ Национальный отчет «Глобальный мониторинг предпринимательства. Россия 2013». URL : http://www.gsom.spbu.ru/images/cms/data/faculty/gem_2013_final20_all.pdf.

\section{Baikal Research Journal}

электронный научный журнал Байкальского государственного университета экономики и права 
индекса предпринимательской активности $Z$, однако эта зависимость является недостаточно сильной. Все коэффициенты парной корреляции значимы, о чем свидетельствуют значения их $t$-статистик, модули которых превышают критическое значение $t$-статистики. Значения же частных коэффициентов корреляции говорят о том, что «чистые» влияния размера субсидий малому предпринимательству на количество малых предприятий меньше влияния индекса предпринимательской активности на тот же показатель.

Другими словами, финансовая поддержка, оказываемая государством, недостаточно сильно стимулирует население заниматься малым предпринимательством, что говорит о необходимости ее доработки. Индекс предпринимательской активности, а именно состояние экономики и предпринимательские настроения в стране оказывают более сильное влияние на состояние малого предпринимательства, чем финансовая поддержка государства.

Следовательно, для преодоления кризиса в моногородах как Иркутской области, так и России в целом, государству необходимо повышать эффективность государственной поддержки субъектов малого предпринимательства для развития этого сектора в монопрофильных городах.

\section{Список использованной литературы}

1. Маслова А. Н. Моногорода в России: проблемы и решения / А. Н. Маслова // Проблемный анализ и государственно-управленческое проектирование. - 2011. — Т. 4, вып. 5. — C. 16-28.

2. Мукосеев Д. В. Экономическая сущность и критерии определения малого предпринимательства / Д. В. Мукосеев / Современные научные исследования и инновации. - 2012. № 5. - URL : http://web.snauka.ru/issues/2012/05/11995.

3. Переверзев М. П. Предпринимательство и бизнес : учебник / М. П. Переверзев, А. М. Лунева. - М. : Инфра-М, 2010. - 176 с.

4. Развитие монопрофильных населенных пунктов в Российской Федерации : сб. науч. тр. / отв. ред. А. Турков. - М. : Финанс. ун-т, 2014. - 341 с.

5. Ризов А. Д. Типологические характеристики моногородов: концептуальный аспект / А. Д. Ризов // Теория и практика общественного развития. - 2014. — № 10. - С. 138-140.

6. Рощина И. В. Влияние градообразующего предприятия на социально-трудовую сферу монопрофильного муниципального образования / И. В. Рощина, Н. А. Дятлова // Известия Иркутской государственной экономической академии. - 2013. — № 3. - С. 25-29.

7. Табачникас Б. И. Экономические границы малого бизнеса: институциальные ограничения и количественные показатели / Б. И. Табачникас // Проблемы современной экономики. - 2012. - № 1. - URL : http://www.m-economy.ru/art.php?nArtId=2423.

8. Титов М. Б. Развитие моногородов России / М. Б. Титов, С. Б. Яшина // Вестник Нижегородского университета им. Н.И. Лобачевского. - 2011. — № 5, ч. 2. - С. 207-210.

9. Фатин Д. С. Перспективы развития малого предпринимательства в России / Д. С. Фатин / Экономические науки. — 2014. — № 11. — URL : http://research-journal.org/featured/ economical/perspektivy-razvitiya-malogo-predprinimatelstva-v-rossii/.

10. Франовская Г. Н. Малый бизнес : учеб. пособие / Г. Н. Франовская. - Воронеж : Воронеж. гос. ун-т, 2007. - $182 \mathrm{c.}$

\section{References}

1. Maslova A. N. Single-industry towns in Russia: problems and solutions. Problemnyi analiz $i$ gosudarstvenno-upravlencheskoe proektirovanie $=$ Problem analysis and public administration projection, 2011, vol. 4, iss. 5, pp. 16-28. (In Russian).

2. Mukoseyev D. V. Economic substance and the criteria for determining small businesses. Sovremennye nauchnye issledovaniya $i$ innovatsii $=$ Modern scientific researches and innovations, 2012, no. 5. Available at: http://web.snauka.ru/en/issues/2012/05/. (In Russian).

3. Pereverzev M. P., Luneva A. M. Predprinimatel'stvo i biznes [Entrepreneurship and business]. Moscow, Infra-M Publ., 2010. 176 p.

\section{Baikal Research Journal}


4. Turkov A. (ed.). Razvitie monoprofil'nykh naselennykh punktov $v$ Rossiiskoi Federatsii [Development of single-industry communities in the Russian Federation]. Moscow, Financial University Publ., 2014. 341 p.

5. Rizov A. D. Typological features of single-industry towns: conceptual aspect. Teoriya $i$ praktika obshchestvennogo razvitiya $=$ Theory and practice of social development, 2014, no. 10, pp. 138-140. (In Russian).

6. Roshchina I. V., Dyatlova N. A. Influence of town-forming enterprise on social and labor sphere of single-industry municipality. Izvestiya Irkutskoy gosudarstvennoy ekonomicheskoy akademii = Izvestiya of Irkutsk State Economics Academy, 2013, no. 3, pp. 25-29. (In Russian).

7. Tabachnikas B. I. Economic borders of small business: institutional limitations and quantitative indicators. Problemy sovremennoi ekonomiki = Problems of Modern Economy, 2012, no. 1. Available at: http://www.m-economy.ru/art.php?nArtId=2423. (In Russian).

8. Titov M. B., Yashina S. B. Development of single-industry towns in Russia. Vestnik Nizhegorodskogo universiteta imeni N.I. Lobachevskogo = Bulletin of Lobachesky State University of Nizhni Novgorod, 2011, no. 5, pr. 2, pp. 207-210. (In Russian).

9. Fatin D. S. Prospects of developing small businesses in Russia. Ekonomicheskie nauki= Economic sciences, 2014, no. 11. Available at: http://research-journal.org/featured/economi$\mathrm{cal} /$ perspektivy-razvitiya-malogo-predprinimatelstva-v-rossii/. (In Russian).

10. Franovskaya G. N. Malyi biznes [Small Business]. Voronezh State University Publ., 2007. $182 \mathrm{p}$.

\section{Информация об авторах}

Скоробогатова Юлия Александровна - доцент, кафедра экономики предприятия и предпринимательской деятельности, Байкальский государственный университет экономики и права, 664003, г. Иркутск, ул. Ленина, 11, e-mail: skorobogatova.ya@gmail.com.

Балдина Анастасия Андреевна - магистрант, кафедра экономики предприятия и предпринимательской деятельности, Байкальский государственный университет экономики и права, 664003, г. Иркутск, ул. Ленина, 11, e-mail: rainbow_nasta7ya@list.ru.

\section{Authors}

Yuliya A. Skorobogatova - Associate Professor, Chair of Enterprise Economy and Entrepreneurship, Baikal State University of Economics and Law, 11 Lenin St., 664003, Irkutsk, Russian Federation; e-mail: skorobogatova.ya@gmail.com.

Anastasiya A. Baldina - Master Degree Student, Chair of Enterprise Economy and Entrepreneurship, Baikal State University of Economics and Law, 11 Lenin St., 664003, Irkutsk, Russian Federation; e-mail: rainbow_nasta7ya@list.ru.

\section{Библиографическое описание статьи}

Скоробогатова Ю. А. Роль малого предпринимательства в социально-экономическом развитии моногородов Иркутской области / Ю. А. Скоробогатова, А. А. Балдина // Baikal Research Journal. — 2015. — T. 6, № 6. — DOI : 10.17150/2411-6262.2015.6(6).13.

\section{Reference to article}

Skorobogatova Yu. A., Baldina A. A. Role of small business in socio-economic development of single-industry towns in Irkutsk Oblast. Baikal Research Journal, 2015, vol. 6, no. 6. DOI: 10.17150/2411-6262.2015.6(6).13. (In Russian).

\section{Baikal Research Journal}

